\title{
COMPORTAMENTO DE CULTIVARES DE UVA SEM SEMENTES NO SUBMÉDIO SÃO FRANCISCO ${ }^{1}$
}

\author{
PATRÍCIA COELHO DE SOUZA LEÃO2
}

\begin{abstract}
RESUMO - Com o objetivo de introduzir, avaliar e selecionar variedades de uva sem sementes, adaptadas às condições tropicais semi-áridas e oferecer novas alternativas aos viticultores do Vale do São Francisco, implantou-se, em 1994, uma coleção com dezenove variedades de uvas sem sementes no Campo Experimental de Bebedouro, da Embrapa Semi-Árido, em Petrolina - PE. Foram avaliadas treze variedades ao longo dos anos de 1997 e 1998 , correspondendo a cinco ciclos de produção. As variedades utilizadas foram Vênus, Arizul, Beauty Seedless, Thompson Seedless, Marroo Seedless, Canner, CG 39915, Pasiga, Saturn, Emperatriz, A1581, Paulistinha e Loose Perlette, enxertadas sobre o porta-enxerto IAC 572 ('Campinas'). Foram avaliados aspectos relacionados ao desenvolvimento vegetativo e produtivo das plantas e características e composição química dos frutos. Todas as variedades apresentaram cachos com tamanho pequeno. As variedades Vênus e Marroo Seedless destacaram-se em relação ao diâmetro de bagas, apresentando, respectivamente, 17,83 e 18,26 mm, sem a necessidade de aplicação de reguladores de crescimento. O teor de sólidos solúveis totais foi elevado na maioria das variedades, enquanto a acidez total titulável foi reduzida, resultando em relações SST/ATT satisfatórias. As variedades Vênus e Marroo Seedless foram as mais produtivas, com produtividades anuais de 24 t/ha e $20 \mathrm{t} / \mathrm{ha}$, respectivamente.
\end{abstract}

Termos para indexação: videira, Vitis vinifera L., produção, características do fruto

\section{BEHAVIOR OF GRAPE SEEDLESS VARIETIES IN THE VALLEY OF SÃO FRANCISCO RIVER}

ABSTRACT - The present work aimed at evaluating and selecting seeddless grape varieties adapted to the semi-arid tropical conditions of the São Francisco River Valley, Northeastern - Brazil. The experiment was carried out in an experimental vineyard which belongs to Embrapa Semi-Árid, in Petrolina, Pernambuco State, Brazil during five growing seasons in 1997 and 1998. The varieties tested were: Vênus, Arizul, Beauty Seedless, Thompson Seedless, Marroo Seedless, Canner, CG 39915, Pasiga, Saturn, Emperatriz, A1581, Paulistinha and Loose Perlette, grafted on IAC 572 ('Campinas') rootstock. Aspects of vegetative and productive characteristics and chemical composition of the berries were evaluated. All varieties presented small bunches, and 'Vênus' and 'Marroo Seedless' berries showed mean diameters of 17.83 and 18.26 mm, respectively, without necessity to apply growth regulators. The total soluble solids (TSS) was high in most varieties. However, the total tritable acidity (TTA) was low, resulting in satisfactory ratio (TSS/ATT). 'Vênus' and 'Marroo Seedless' were the most productive varieties, with the annual average production of 24 tons/ha and 20 tons/ha, respectively.

Index terms: grapevine, Vitis vinifera L., yield, bunch characteristics.

\section{INTRODUÇÃO}

A produção de uvas de mesa sob condições irrigadas, na região semi-árida do Nordeste do Brasil, concentra-se às margens do Rio São Francisco, com uma área plantada em 2000 de 4487 ha e uma produtividade de 30 toneladas/ha/ano em duas safras, o que significa um rendimento econômico médio de 80 milhões de dólares (Agrianual, 2001). A maior parte das áreas está ocupada por variedades com semente, mas este quadro está mudando gradativamente. A partir da década de noventa, foram introduzidas comercialmente variedades sem sementes que só recentemente adquiriram expressão econômica, pela demanda do mercado externo, preços elevados em relação à uva com semente e grande aceitabilidade pelo mercado consumidor nacional e internacional.

O mercado para uva de mesa sem semente é extremamente atraente. O Chile exportou, na safra 1999/2000, 76,2 milhões de caixas de 5kg de uvas de mesa, sendo 42,3 milhões de caixas para os Estados Unidos (Bown, 2000). Nesse contexto a produção de uva sem semente nesta região vem crescendo rapidamente, resultando em uma maior mobilidade mercadológica para o viticultor do Vale do São Francisco.

No entanto, as variedades sem sementes, devido às dificuldades de adaptação às condições tropicais do semi-árido nordestino, apresentam produções reduzidas e irregulares, resultado de sua baixa fertilidade de gemas, desgrane elevado e suscetibilidade à rachadura do pedicelo em condições de chuva durante a fase de maturação, além de elevada suscetibilidade a doenças, especialmente ao cancro bacteriano, causando grandes prejuízos aos viticultores desta região.

Silva et al. (1998), em levantamento de demandas prioritárias de pesquisa para o Vale do Rio São Francisco, identificaram, como um dos principais problemas tecnológicos, a necessidade de desenvolvimento de novas variedades de uvas sem sementes de acordo com a tendência de comercialização de uvas de mesa no mundo.

O presente trabalho teve como objetivos avaliar aspectos relacionados ao crescimento vegetativo e produtivo das plantas e as carac- terísticas e composição química dos frutos de treze variedades de uvas sem sementes durante cinco ciclos de produção, a fim de selecionar-se aquelas melhor adaptadas às condições tropicais semi-áridas.

\section{MATERIALEMÉTODOS}

O experimento foi conduzido no Campo Experimental de Bebedouro, pertencente à Embrapa Semi-Árido, localizado no município de Petrolina-PE, latitude $9^{\circ} 09^{\prime}$ Sul , longitude $40^{\circ} 22$ ' Oeste e altitude média de 365,5 metros.

Segundo a classificação de Köeppen, o clima da região pode ser classificado como tipo Bswh, que corresponde a uma região semiárida muito quente. O índice pluviométrico anual é de $571,5 \mathrm{~mm}$. A temperatura média anual é de $26,4^{\circ} \mathrm{C}$, com média das mínimas de $20,6^{\circ} \mathrm{C}$, e média das máximas $31,7^{\circ} \mathrm{C}$. Os dados climáticos referentes ao período estudado são apresentados na Figura 1.

$\mathrm{O}$ vinhedo no qual se realizou o experimento foi composto por uma coleção de variedades de uva sem sementes, implantado em setembro de 1994, utilizando-se como porta-enxerto da cv. IAC 572 'Campinas'. O sistema de condução empregado foi a latada, com espaçamento de 4 x 2 m (1250 plantas/ha), e sistema de irrigação localizada do tipo gotejamento. O período considerado no estudo correspondeu aos anos de 1997 e 1998, sendo efetuadas avaliações de cinco ciclos de produção. As datas de poda foram 14-01-1997, 16-06.-997, 13-11-1997, 25-03-1998 e 10-08-1998.

A coleção foi composta por variedades de uva sem sementes procedentes do Banco Ativo de Germoplasma (BAG) de videira da Embrapa Uva e Vinho, em Bento Gonçalves-RS: Emerald Seedless, Flame Seedless, Ruby Seedless, Emperatriz, Arizul, Paulistinha, Marroo Seedless, Saturn, Canner, A1105, Thompson Seedless, Delight, CG 39915, Pasiga, Loose Perlette, Beauty Seedless, A1581, Vênus e Moscatuel. Entretanto, Emerald Seedless, Flame Seedless, Ruby Seedless, A1105, Delight e Moscatuel foram eliminadas da coleção, tendo em vista a sua 
alta suscetibilidade à infecção causada pelo fungo Botriodiplodia theobromae e, portanto, não foram incluídas nas avaliações.

As plantas foram conduzidas com um braço primário e formação do tipo 'espinha de peixe', isto é, braços secundários laterais dispostos simetricamente e perpendicular ao braço principal. Foram realizadas podas de produção mistas com varas e esporões, sendo as varas mantidas com aproximadamente sete a nove gemas. Para a quebra de dormência, foram pulverizados todos os ramos podados com cianamida hidrogenada (Dormex) à concentração de 5\%. O manejo da copa compreendeu ainda operações de desbrota, desnetamento, desfolha, desponte dos ramos e raleio de bagas. As adubações, manejo da irrigação e tratamentos fitossanitários foram realizados de acordo com as recomendações para a cultura da videira nesta região (Souza Leão, 2000).

Os cachos foram caracterizados utilizando-se das seguintes variáveis: peso médio $(\mathrm{g})$, comprimento e largura $(\mathrm{cm})$, formato e compacidade. Foram identificadas, no início do primeiro ciclo de produção, três plantas para avaliação do peso médio, comprimento e largura dos cachos, registrando-se os dados de todos os cachos da planta. Para avaliação de formato e compacidade predominante dos cachos, efetuouse observação visual em uma planta que foi mantida sem a realização de raleio de bagas para esta finalidade. Todas as avaliações foram realizadas após a colheita dos frutos.

Para a avaliação das características das bagas, foram avaliados o comprimento (mm), diâmetro $(\mathrm{mm})$, peso médio $(\mathrm{g})$, formato, sabor, consistência da polpa, coloração, uniformidade de coloração e aderência ao pedicelo. O comprimento, diâmetro e peso médio foram determinados em cinco cachos tomados ao acaso, nas três plantas utilizadas para avaliação das características dos cachos. Considerou-se como amostra para avaliação do comprimento, diâmetro e peso das bagas a média de dez bagas de cada cacho, isto é, cinqüenta bagas por planta ou repetição. O formato, coloração, uniformidade de coloração e aderência ao pedicelo foram determinados por observação visual, enquanto o sabor e consistência da polpa, por análise sensorial.

As análises do teor de sólidos solúveis totais (SST) e acidez total titulável (ATT) foram realizadas após a colheita dos frutos no laboratório de Fisiologia Vegetal da Embrapa Semi-Árido. Utilizou-se como amostra o suco extraído de cinquienta bagas por planta e três plantas ou repetições. Tomou-se uma gota deste suco para leitura do teor de sólidos solúveis totais ( ${ }^{\circ}$ Brix) em refratômetro. A acidez total titulável foi determinada pela utilização de uma alíquota de cinco ml do suco de uva misturado a quinze $\mathrm{ml}$ de água destilada. Esta amostra foi titulada com $\mathrm{NaOH}$ a $0,1 \mathrm{~N}$ padronizado, tendo como indicador a fenolftaleína $0,1 \%$, expressando-se os resultados em gramas de ácido tartárico. $100 \mathrm{ml}$ de $\operatorname{suco}^{-1}$.
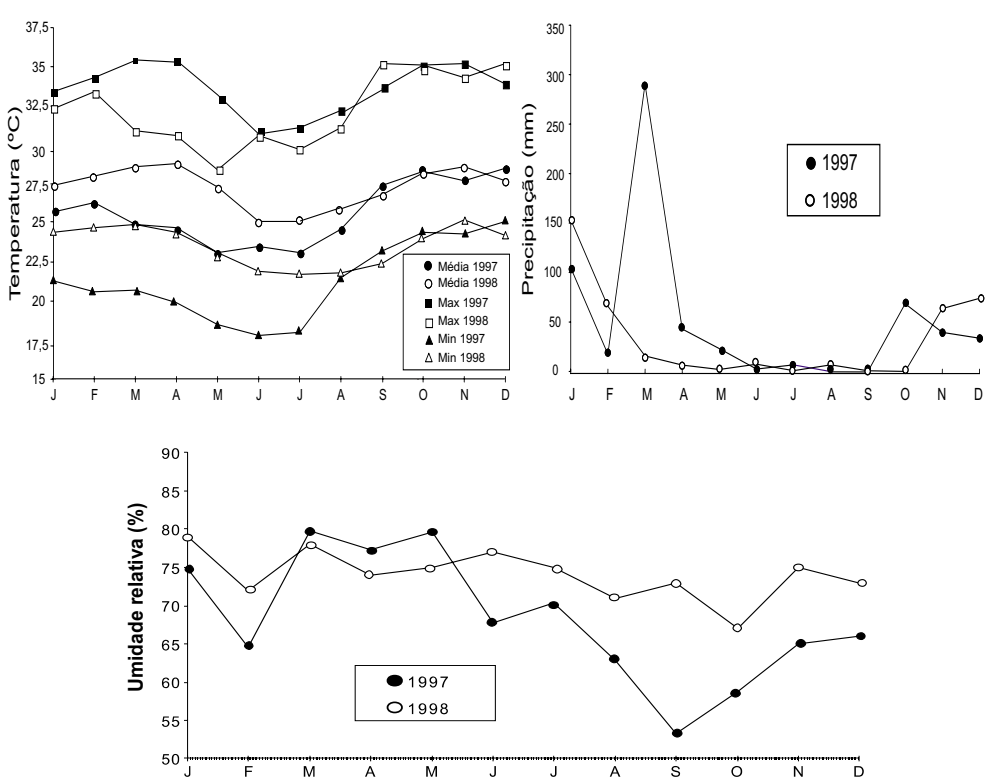

FIGURA 1 - Médias mensais de temperatura, precipitação e umidade relativa durante os anos de 1997 e 1998, Petrolina-PE.
Com os dados obtidos, determinou-se a relação sólidos solúveis totais/acidez total titulável ("ratio") que foi expressa pela relação ${ }^{\circ}$ Brix/Acidez.

$\mathrm{O}$ vigor das plantas foi avaliado através do peso dos ramos de poda em $\mathrm{kg} / \mathrm{planta}$, determinados pelo peso médio de todos os ramos sem folhas da planta coletados no momento da poda, considerando-se treze repetições (plantas) por variedade.

A produção foi obtida pela soma total do peso de todos os cachos da planta (kg/planta). Para determinação da produção média e número de cachos por planta, foram utilizadas treze plantas ou repetições.

As variedades foram caracterizadas utilizando-se como critério os descritores propostos pelo International Plant Genetic Resources Institute (1997).

\section{RESULTADOSE DISCUSSÃO}

Pode-se observar, pela Tabela 1, que os menores pesos dos ramos foram obtidos na variedade Vênus em todos os ciclos, indicando o menor vigor demonstrado por esta variedade. A variedade Thompson Seedless apresentou uma média geral de $9,3 \mathrm{~kg}$ de ramos/planta, seguida pela CG 39915 com 7,8 kg, destacando-se como variedades mais vigorosas. Albuquerque (1998) comenta que, em condições de clima tropical, a variedade Thompson Seedless apresenta-se excessivamente vigorosa com ramos que crescem em torno de dez metros de comprimento num período de quatro meses, em detrimento da produção de frutos.

A variedade Vênus foi considerada uma variedade vigorosa, segundo Moore \& Brown (1977) e Camargo \& Mandelli (1993); entretanto, nas condições em que se realizou este trabalho, as plantas de 'Vênus' apresentaram baixo vigor vegetativo.

As variedades Vênus, Marroo Seedless, CG 39915 e Saturn foram as variedades mais produtivas, enquanto 'Emperatriz', 'Thompson Seedless' e 'Loose Perlette' apresentaram as menores médias de produção e número de cachos por planta.

As variedades não apresentaram produção (peso de cachos e número de cachos por planta) estável ao longo do tempo, alternando ciclos de maior produção com outros de produção reduzida. Os valores obtidos para produção (número de cachos e peso médio por planta) e vigor (peso dos ramos), em todas as variedades, demonstram uma relação inversa entre produção de frutos e desenvolvimento vegetativo da planta.

Considerando-se dois ciclos de produção por ano, obtêm-se os seguintes valores para produtividade (t/ha/ano): 24 t/ha em 'Vênus'; 20 t/ha em 'Marroo Seedless'; 18 t/ha em 'CG 39915'; e 17 t/ha em 'Saturn'. As variedades apresentaram produtividades muito inferiores àquelas 30 a 40 t/ha mencionadas para uva Itália no Vale do Rio São Francisco (Albuquerque, 1996; Silva et al., 1998). Entretanto, pode-se observar, pela Tabela 1, que 'Vênus' e 'Marroo Seedless' apresentaram produtividades satisfatórias de, respectivamente, 9,45 e 7,82 kg/planta. Essas variedades demonstram, portanto, um grande potencial para cultivo no Vale do Rio São Francisco.

As produtividades ( $\mathrm{t} / \mathrm{ha}$ ) obtidas nas variedades Vênus e Marroo Seedless são inferiores àquelas observadas por Camargo et al. (1997) em 'Perlette' e 'Centennial Seedless', mas semelhantes à produtividade das variedades 'Flame Seedless', 'Moscatuel' e 'Catalunha', nesta mesma região.

O peso médio dos cachos para os cinco ciclos de produção variou entre $73 \mathrm{~g}$ na variedade Paulistinha a $231 \mathrm{~g}$ na variedade Emperatriz.

Segundo a classificação proposta pelo International Plant Genetic Resources Institute (1997), todas as variedades apresentaram peso médio de cachos baixo. Isto realmente pode ser verificado quando estes resultados são comparados àqueles obtidos em outras variedades no Vale do Rio São Francisco.

O comprimento e largura médios dos cachos demonstrou, em todas as variedades, a mesma tendência de alternância entre os ciclos de produção ou datas de poda observadas em relação ao peso médio de cachos, isto é, os cachos aumentaram os seus comprimento e largura do 
$1^{\circ}$ para o $2^{\circ}$ ciclo, diminuindo nos dois ciclos seguintes e voltando a aumentar no $5^{\circ}$ ciclo.

De acordo com os descritores propostos pelo International Plant Genetic Resources Institute (1997), pode-se observar que a maioria das variedades apresentaram cachos curtos; apenas os cachos de 'Arizul', 'Beauty Seedless', 'Canner', 'Emperatriz' e 'CG 39915' podem ser classificados com comprimento médio. Os comprimentos de cachos obtidos são inferiores aos 20,0 cm que menciona Gayet (1993) como adequados em uvas para exportação.

Este comportamento oscilante na qualidade dos cachos e, conseqüentemente, na produtividade ao longo de ciclos sucessivos de produção ocorre com freqüência em condições tropicais. Alguns fatores que podem contribuir para esta situação, são a redução da capacidade produtiva e vigor das plantas observadas após sobrecargas de produção, deficiências no manejo e alterações climáticas associados a maior incidência de doenças.

Os resultados obtidos para as características de peso médio, comprimento e largura dos cachos foram inferiores àqueles encontrados na literatura em outras regiões para estas variedades, evidenciando que as condições climáticas do Vale do Rio São Francisco (Figura 1) não permitiram uma plena expressão das características varietais.

As variedades não apresentaram um tamanho semelhante de bagas nos cinco ciclos de produção. As épocas de poda que foram mais favoráveis ao crescimento de bagas em uma determinada variedade, nem sempre repetiram este efeito nas demais variedades. Apesar disso, pode ser observada uma tendência de o $1^{\circ}$ ciclo resultar em bagas de maiores comprimento e diâmetro para a maioria das variedades.

Conforme pode ser observado pela Tabela 1, as variedades Emperatriz e A1581 destacaram-se com os maiores comprimentos médios de bagas, apresentando, respectivamente, para os cinco ciclos, uma média de 23,0 e 22,6 mm. Por sua vez, as variedades A1581 e Marroo Seedless apresentaram os maiores diâmetros, ou seja 19,5 e $18,3 \mathrm{~mm}$, respectivamente. O maior tamanho das bagas da variedade A1581, em todos os ciclos de produção estudados, pode ser justificado pelo fato de a mesma ter apresentado sementes, favorecendo a produção de hormônios de crescimento no interior da baga. Estas diferenças observadas entre as variedades quanto ao tamanho de bagas eram esperadas, uma vez que esta característica possui elevado controle genético e depende do formato da baga de cada variedade. Os tamanhos de bagas obtidos são semelhantes aos encontrados por Camargo et al. (1997) e Souza Leão et al. (1999) em outras variedades de uva sem sementes, na mesma região deste estudo.

É possível, de acordo com os resultados obtidos para comprimento de bagas, classificar as variedades Vênus, Arizul, Beauty Seedless, Marroo Seedless, Pasiga, Paulistinha e Loose Perlette como variedades de tamanho médio de bagas, enquanto 'Canner', 'Thompson Seedless', 'CG 39915', 'Saturn', 'Emperatriz' e 'A1581' podem ser consideradas de tamanho mediano a grande.

O diâmetro das bagas, geralmente, é a principal variável utilizada como medida para avaliar-se o tamanho das bagas de uma determinada variedade. Segundo Carraro \& Cunha (1994) citados por Gonçalves (1996), as normas de qualidade para exportação de uvas de mesa para os Estados Unidos, na classe US Extra, exigem um diâmetro de bagas mínimo de 17,5 mm para variedades de uva sem sementes. De acordo com os resultados apresentados na Tabela 3, as variedades Vênus, Marroo Seedless, Pasiga, Saturn, Emperatriz e A1581 atendem a estes padrões de qualidade.

As variedades A 1581, Marroo Seedless e Vênus destacaramse com as maiores médias para peso de bagas (Tabela 1). De acordo com os descritores do International Plant Genetic Resources Institute (1997), todas as variedades, com exceção de 'Vênus', 'Marroo Seedless', 'Pasiga', 'Emperatriz' e 'A 1581' apresentaram baixo peso médio de bagas. Estas, por sua vez, podem ser classificadas com peso de bagas mediano.

As diferenças observadas no tamanho das bagas, nas dife- rentes épocas de poda, pode ser devido a influência da temperatura (Figura 1) sobre o crescimento das bagas.

É importante salientar que os resultados podem ser considerados satisfatórios, uma vez que não foram utilizados reguladores de crescimento para aumentar o tamanho das bagas, ou seja, eles exprimem apenas o potencial genético de cada variedade e sua interação com o ambiente.

As médias para teor de sólidos solúveis totais e acidez total titulável, de maneira geral, apresentam comportamento inversamente proporcional, pois durante a fase de maturação dos frutos, enquanto ocorre a degradação e redução da síntese, principalmente dos ácidos málico e tartárico, observa-se uma acumulação contínua de açúcares, especialmente glicose e frutose (Carvalho \& Chitarra, 1984; Calò et al., 1996). As épocas de poda exerceram grande influência na composição química dos frutos. Entretanto, foram encontradas respostas diferentes das variedades em relação às condições ambientais predominantes em uma determinada época de poda ou ciclo de produção. Estas variações eram esperadas, pois, de acordo com Calo et al. (1996), a expressão quantitativa dessas características que são qualitativas, dependem principalmente da interação entre genótipo e clima, e por este motivo é muito difícil encontrar-se respostas semelhantes em diferentes épocas.

'Vênus' destacou-se com a maior média para sólidos solúveis totais (Tabela 1). Apenas as variedades Pasiga, CG 39915 e Canner apresentaram teor de sólidos solúveis totais inferior ao mínimo recomendado de $15^{\circ}$ Brix para a região do Vale do Rio São Francisco (Gayet, 1993; Albuquerque, 1996).

Quanto à acidez total titulável, Carvalho \& Chitarra (1984) comentam que valores acima de $1,5 \%$ podem ser considerados elevados; entretanto, as médias, em todas as variedades, foram inferiores a $1,0 \mathrm{~g}$ de ácido tartárico. $100 \mathrm{ml}$ de $\mathrm{suco}^{-1}$, o que significa que todas elas apresentaram baixa acidez, consequiência também das elevadas temperaturas da região, que, segundo Calò et al. (1996), favorecem a redução da acidez dos frutos.

As variedades Vênus, Marroo Seedless, Saturn e CG 39915 apresentaram as maiores médias para a relação SST/ATT, enquanto em 'Arizul', 'A1581'e 'Emperatriz' foram obtidos os menores valores. De acordo com as médias apresentadas na Tabela 1, pode-se observar que todas as variedades, com exceção de 'Arizul', 'A1581'e 'Emperatriz', apresentaram valores de relação SST/ATT iguais ou superiores àqueles mencionados por Gayet (1993). O equilíbrio entre açúcares e ácidos totais obtidos neste trabalho, segundo Carvalho \& Chitarra (1984) permite inferir-se do sabor agradável apresentado pelas variedades.

De acordo com os descritores do International Board for Plant Genetic Resources (1997), as variedades Vênus, Thompson Sedless, Saturn e Paulistinha são classificadas com médios teores de sólidos solúveis totais, enquanto, em 'Beauty Seedless', 'CG 39915', 'Pasiga', 'Canner' e 'Emperatriz', estes teores foram baixos. Em relação à acidez total titulável, as médias obtidas para os cinco ciclos indicam que todas as variedades, com exceção de CG 39915 e Saturn, apresentam conteúdo médio de acidez.

Pode-se observar que as condições climáticas do Vale do Rio São Francisco, com temperaturas médias elevadas durante a fase de maturação, favorecem uma maior concentração de açúcares e a redução da acidez nos frutos, contribuindo para a melhoria do sabor e qualidade da uva.

Em relação às características qualitativas dos cachos e bagas, pode-se observar pela Tabela 2 que as variedades apresentaram colorações verde, amarela, rosada e preta. $\mathrm{O}$ formato das bagas pode ser classificado como ovóide, elíptica ou globosa, e a consistência da polpa, segundo a variedade, foi mucilaginosa, fundente, carnosa ou crocante. As variedades apresentaram ainda variações quanto à sua resistência ao desgrane de bagas, destacando-se a 'Pasiga', 'Arizul', 'Beauty Seedless', 'Canner' e 'Marroo Seedless' pelo seu baixo desgrane. 
TABELA 1 - Características agronômicas de treze variedades de uvas sem sementes, valores médios de cinco ciclos de produção, Petrolina-PE, 1997-1998.

\begin{tabular}{|c|c|c|c|c|c|c|c|c|c|c|c|c|c|}
\hline Caracteristicas & Vênus & Arizul & Beauty & Thompson & Marroo & Canner & CG & Pasiga & Saturn & Emperatriz & A1581 & Paulistinha & Loose \\
\hline & & & Seedless & & Seedless & & 39915 & & & & & & Perllete \\
\hline $\begin{array}{c}\text { Peso da poda } \\
(\mathrm{kg})\end{array}$ & 1,5 & 2,9 & 2,4 & 9,3 & 3,9 & 5,8 & 7,8 & 6,7 & 4,8 & 6,5 & 5,7 & 5,8 & 6,7 \\
\hline $\mathrm{N}^{\mathrm{N} d e}$ cachos & 61 & 28 & 35 & 15 & 48 & 13 & 28 & 20 & 68 & 6 & 35 & 57 & 24 \\
\hline $\begin{array}{l}\text { Produ } 0 \\
\text { (kgplanta) }\end{array}$ & 9,5 & 6,2 & 6,2 & 2,4 & 7,8 & 2,7 & 3,8 & 4,2 & 6,6 & 1,4 & 6,3 & 4,4 & 2,4 \\
\hline $\begin{array}{l}\text { Peso de cachos } \\
\text { (g) }\end{array}$ & 171 & 213 & 200 & 163 & 170 & 219 & 128 & 163 & 106 & 231 & 180 & 73 & 94 \\
\hline $\begin{array}{l}\text { Compr. de cachos } \\
\text { (cm) }\end{array}$ & 14,5 & 16,7 & 15,8 & 13,7 & 12,7 & 16,7 & 15,1 & 14,0 & 12,0 & 16,4 & 12,9 & 12,0 & 13,6 \\
\hline $\begin{array}{l}\text { Largura de cachos } \\
\text { (cm) }\end{array}$ & 9,1 & 10,3 & 10,4 & 8,5 & 9,4 & 9,7 & 8,5 & 9,0 & 7,8 & 10,6 & 8,4 & 5,7 & 7,4 \\
\hline $\begin{array}{l}\text { Compr. de bagas } \\
(\mathrm{mm})\end{array}$ & 19,7 & 18,7 & 17,9 & 20,2 & 19,8 & 21,0 & 21,0 & 19,6 & 21,6 & 23,0 & 22,6 & 17,3 & 17,6 \\
\hline $\begin{array}{l}\text { Diâmetro de } \\
\text { bagas (mm) }\end{array}$ & 17,8 & 16,1 & 15,8 & 15,9 & 18,3 & 16,4 & 15,0 & 17,6 & 15,9 & 17,7 & 19,5 & 14,2 & 15,4 \\
\hline $\begin{array}{c}\text { Peso de bagas } \\
\text { (g) }\end{array}$ & 3,9 & 2,8 & 2,4 & 2,7 & 4,0 & 2,9 & 2,9 & 3,7 & 3,0 & 3,7 & 4,8 & 2,1 & 2,3 \\
\hline SST & 19,6 & 16,6 & 18,0 & 18,2 & 16,1 & 13,8 & 15,4 & 14,4 & 18,9 & 12,9 & 16,5 & 18,3 & 17,1 \\
\hline ATT & 0,73 & 0,91 & 0,91 & 0,91 & 0,66 & 0,63 & 0,55 & 0,68 & 0,57 & 0,70 & 0,88 & 0,81 & 0,78 \\
\hline $\begin{array}{l}\text { Rela } 0 \\
\text { SST/ATT }\end{array}$ & 28,0 & 19,7 & 22,4 & 21,5 & 25,0 & 22,7 & 29,1 & 22,8 & 34,2 & 18,9 & 19,3 & 25,3 & 22,5 \\
\hline
\end{tabular}

${ }^{1} \mathrm{SST}=$ Sólidos Solúveis Totais medido em ${ }^{\circ}$ Brix

${ }^{2} \mathrm{ATT}=$ Acidez Total Titulável medido em g de ácido tartárico/100 ml de suco

TABELA 2 - Características dos cachos de treze variedades de uvas sem sementes em cinco ciclos de produção, Petrolina PE, 1997-1998.

\begin{tabular}{|c|c|c|c|c|c|c|c|c|}
\hline VARIEDADE & COLORA 0 & UNIFORMIDADE & $\begin{array}{c}\text { FORMATO } \\
\text { BAGAS }\end{array}$ & $\begin{array}{c}\text { FORMAT0 } \\
\text { CAHOS }\end{array}$ & COMPACIDADE & SABOR & CONSISTÊNCIA & $\begin{array}{l}\text { DESGRANE } \\
\text { DE BAGAS }\end{array}$ \\
\hline Vênus & Preta & Uniforme & Globosa & Cônico & $\begin{array}{c}\text { Muito } \\
\text { Compacto }\end{array}$ & Especial & Mucilaginosa & Alto \\
\hline Cg 39915 & Rosada intensa & Desuniforme & Eliptica & Cilindrico & Compacto & Neutro & Carnosa & Alto \\
\hline A1581 & Preta & Uniforme & Ovíide & Cônico & Compacto & Especial & Crocante & Alto \\
\hline Pasiga & Preta & Desuniforme & Ovóide & Cônico & Muito compacto & Neutro & Carnosa & Baixo \\
\hline Arizul & Verde amarelada & Uniforme & Globosa & Cilindrico & Muito compacto & Neutro & Carnosa & Baixo \\
\hline Beauty Seedless & Preta & Uniforme & Globosa & Cônico & Muito compacto & Especial & Fundente & Baixo \\
\hline Canner & Verde amarelada & Uniforme & Eliptica & Cônico & Muito compacto & Neutro & Crocante & Baixo \\
\hline $\begin{array}{l}\text { Thompson } \\
\text { Seedess }\end{array}$ & $\begin{array}{c}\text { Verde } \\
\text { Amarelada }\end{array}$ & Uniforme & Eliptica & Cônico & Muito Compacto & Neutro & Crocante & Médio \\
\hline Paullistinha & Verde amarelada & Uniforme & Ovóide & Cilindrico & Muito compacto & $\begin{array}{l}\text { Especial } \\
\text { foxado }\end{array}$ & Fundente & Alto \\
\hline Loose Perlette & Verde amarelada & Uniforme & Ovóide & Cilindrico & Muito compacto & Especial & Crocante & Médio \\
\hline Marroo Seedless & Rosada intensa & Uniforme & Ovóide & Cônico & Muito compacto & Neutro & Carnosa & Baixo \\
\hline Saturn & Vermelha & Desuniforme & Ovóide & Cilindrico & Compacto & Especial & Crocante & Alto \\
\hline Emperatriz & $\begin{array}{r}\text { Rosada } \\
\text { Fraca }\end{array}$ & Desuniforme & Eliptica & Cônico & Compacto & Neutro & Carnosa & Baixo \\
\hline
\end{tabular}

\section{CONCLUSÕES}

1. As variedades Vênus e Marroo Seedless demonstraram grande potencial para cultivo nas condições do Vale do São Francisco, com produtividades superiores a $20 \mathrm{t}$ ha/ano.

2. Nas condições de cultivo, o vigor excessivo inviabilizou a produção comercial das variedades Emperatriz, Thompson Seedless, Loose Perllete e Canner, e as produtividades médias evidenciam boas possibilidades para Vênus e Marroo Seedless.
3. Quanto aos cachos e bagas, verificou-se que, com exceção da 'Vênus', as demais variedades produziram cachos com características inferiores aos respectivos padrões varietais. As variedades Vênus e Marroo Seedless apresentaram cachos que atendem aos padrões de qualidade para exportação. O teor de SST e ATT foram satisfatórios na maioria das variedades.

\section{REFERÊNCIASBIBLIOGRÁFICAS}

AGRIANUAL. 2000: Anuário da agricultura brasileira. São Paulo: FNP, Consultórios e Comércio, 2001, p. 532-542, 2001.

ALBUQUERQUE, T.C.S. de. Uvas para exportação: aspectos técnicos da produção. Brasília: EMBRAPA-SPI, 1996. 53p. (Série Publicações Técnicas FRUPEX, 25).

ALBUQUERQUE, T.C.S. de. Absorção de macronutrientes pelas cultivares de videira Thompson Seedless e Itália sob efeito de diferentes retardantes de crescimento e porta-enxertos. 1998. 63f. Tese (Doutorado em Solos e Nutrição de Plantas) - Escola Superior de Agricultura Luís de Queiroz, Universidade de São Paulo, Piracicaba, 1998

BOWN, R. Chilean table grape industry: production, exports, market and prospects. In:INTERNATIONAL SYMPOSIUM ONTABLE GRAPE, 4., 2000, La Serena. Abstracts... La Serena:INIA, 2000, p.98-121

CALÒ, A.; TOMASI, D.; CRESPAN, M.; COSTACURTA, A. Relationship between environmental factors and the dynamics of growth of the grapevine. Acta Horticulturae, Wageningen, v.427, p. 217$31,1996$.

CAMARGO, U. A., MANDELLI, F. Vênus, uva precoce para mesa. Bento Gonçalves: EMBRAPA-CNPUV, 1993.4p. (Comunicado Técnico,13).

CAMARGO, U. A.; MASHIMA, C. H.; CZERMAINSKI, A. B. C. Avaliação de cultivares de uvas apirênicas no Vale do São Francisco. Bento Gonçalves: EMBRAPA/CNPUV, 1997. 8p. (Comunicado Técnico, 26).

CARVALHO, V. D.; CHITARRA, M. I. F. Aspectos qualitativos da uva. Informe Agropecuário, Belo Horizonte, v.10, n.117, p.75-9, 1984.

GAYET, J. P. Características das frutas de exportação. In: GORGATTI NETTO, A., GAYET, J. P., BLEINROTH, E. F. G.; MATALLO, M.; GARCIA, E.; GARCIA, A. E.; ARDITO, E. F. G., BORDIN, M. Uvas para exportação, procedimentos de colheita e pós-colheita. Brasília: EMBRAPA-SPI, 1993. 40p. (Série Publicações Técnicas FRUPEX, 2).

GONÇALVES, C. A. A. Estrutura de produção e de mercado da uva de mesa brasileira. Agricultura em São Paulo, v.43, n.1, p.43-93, 1996.

INTERNATIONAL PLANT GENETIC RESOURCES INSTITUTE. Descriptors for grapevine (Vitis spp.). Rome, 1997. 62p. il.

MOORE, J. N.; BROWN, E. 'Venus' grape. HortScience, Alexandria, v.12, n.6, p.585, 1977.

SILVA, P. C. G. da, LEÃO, P. C. de SOUZA; CERDAN, C., DENIS, S.; CHOUDHURY, M. M., BENTZEN, M. da C. P.; BARRETO, M. C. A cadeia produtiva da uva de mesa do Nordeste do Brasil. In: CASTRO, A. M. G. de; LIMA, S. M. V., GOEDERT, W. J., FILHO, A. de F.; VASCONCELOS, J. R. P. Cadeias produtivas e sistemas naturais: prospecção tecnológica. Brasília: EMBRAPA-SPI, 1998. p.529-64.

SOUZA LEÃO, P. C. de; JÚNIOR LINO, E. da C.; SANTOS, E. da S. Efeitos do CPPU e ácido giberélico sobre o tamanho de bagas da uva Perlette cultivada no Vale do São Francisco. Revista Brasileira de Fruticultura, Cruz das Almas, v. 21, n. 1, p. 74-78, 1999.

SOUZA LEÃO, P. C. de. Implantação do pomar e manejo da cultura. In: SOUZA LEÃO, P. C. de; SOARES, J. M. (Ed.). A vitultura no semi-árido brasileiro. Petrolina:Embrapa Semi-Árido, 2000. Cap.6, p. 93-128. 